\title{
Why do central arachnoid pouches expand?
}

\author{
BERNARD WILLIAMS AND A. N. GUTHKELCH \\ From the Midland Centre for Neurosurgery, Warley, and the \\ Combined Neurological Service, Hull Royal Infirmary, Hull
}

SYNOPSIS Three cases of progressive hydrocephalus, two occurring in infants and one in a 12 year old girl who also exhibited precocious puberty, were found to be associated with large arachnoid pouches originating within the posterior fossa. The pathogenesis of such cysts is discussed with special reference to the possibility that their progressive distension results from CSF pulsations of venous origin. Both a direct method of treatment (opening the cyst into the adjacent subarachnoid space) and an indirect one (insertion of a ventriculo-atrial shunt) have been used with success.

Cysts or pouches in the subarachnoid space may cause distortion and obstruction of the cerebrospinal fluid (CSF) pathways, although themselves in free communication with the rest of the subarachnoid space. In this paper we present three cases of centrally situated arachnoid cyst which gave rise to hydrocephalus and all the signs of a space-occupying lesion, and discuss their physiopathology with special reference to the cause of their enlargement.

\section{CASE 1}

A 1 month old baby born normally at full term was referred in February 1967 because of a rapidly enlarging head.

On examination she was of normal physical development (weight $4,240 \mathrm{~g}$ ) but very quiet. The head circumference was $40.2 \mathrm{~cm}$, the fontanelle full; there was coronal and sagittal sutural diastasis. The fundi were normal. The right eye was displaced somewhat downwards and outwards relative to the left
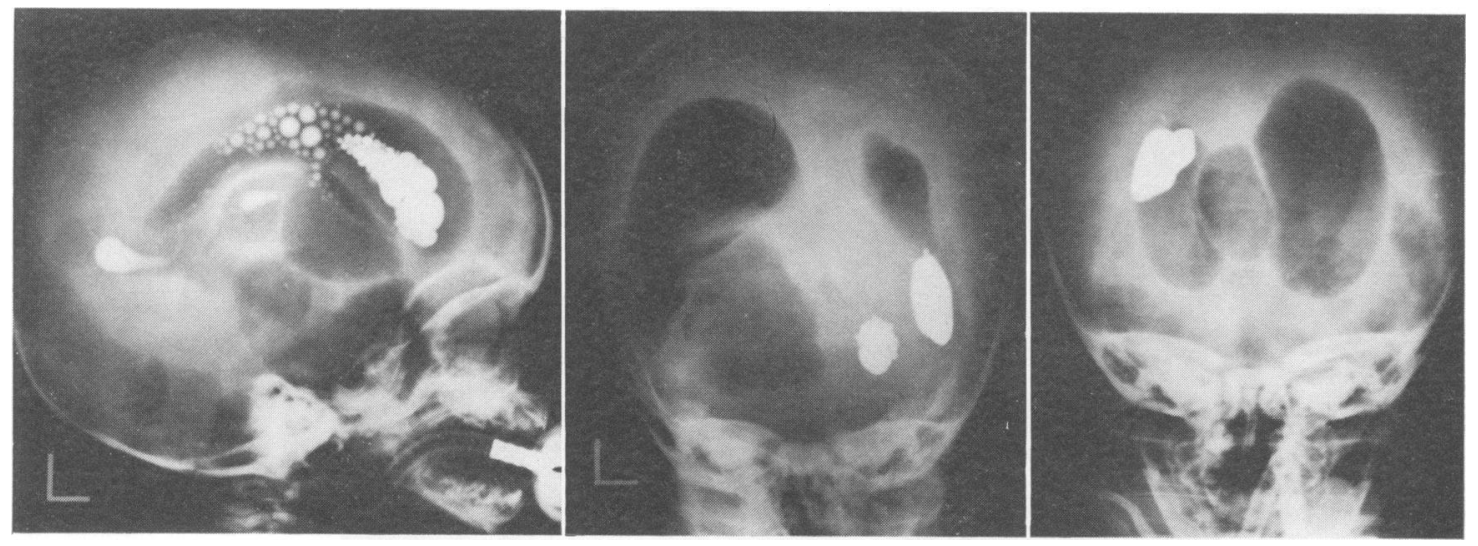

FIG. 1 (left). Case 1. A vertical-ray lateral radiograph showing iophendylate in the right lateral ventricle and air outlining a hydrocephalus. There appear to be a cavum septi pellucidi and a cavum vergae as well as a multiloculated pouch in the basal subarachnoid space. FIG. 2 (centre). Case 1. Towne view of the ventriculogram confirming the location and the multiloculated appearance of the abnormal pouch. FIG. 3 (right). Case 1. Brow-up AP view confirming the existence of a cavum septi pellucidi. 
with loss of inward and upward movement but no ptosis. The pupils were of normal size, equal and reacting to light. There was some limb hypotonia.

Ventriculography with iophendylate showed evidence of ventricular dilatation but the opaque medium could not be made to pass through the foramen of Monro. Air was therefore introduced and it was seen that the left lateral ventricle was larger than the right with some shift of the midline structures to the right. A large cavum septi pellucidi was present and behind this the posterior end of the third ventricle was grossly elevated and displaced backwards by a multilocular air-filled cavity occupying much of the left middle fossa as well as the basal cisterns on the left side (Figs 1-3).

After this procedure the child became drowsy and vomited for two days but then recovered to her preoperative status. Exploration was performed seven days after the ventriculography.

At operation, a left temporal craniotomy was carried out. On retracting the temporal lobe an enormous arachnoid cyst was seen occupying the anterior half of the posterior fossa and protruding through the tentorium under the temporal lobe itself. Its walls were thin but slightly opaque and were crossed by the third and fourth cranial nerves. The cyst was opened widely at tentorial level after which the cerebral hemisphere was re-expanded by refilling the lateral ventricle with saline.

Immediately after the operation the child's condition appeared satisfactory but she collapsed and died a few hours later.

At necropsy there was some residual collapse of the left hemisphere at the site of the craniotomy but the maximum depth of the subdural space did not exceed $1.5 \mathrm{~cm}$. There was a large arachnoid cyst occupying the position indicated by the ventriculograms and containing sufficient fresh blood to explain the child's collapse. Posteriorly it was attached to the anterior aspect of the brain stem and left cerebellar hemisphere, superiorly to the floor of the third ventricle, and anteriorly to the tips of both temporal lobes; its inferior surface lay along the base of the skull. The ventriculogram had already shown that this cyst was in free communication with the CSF pathways and the necropsy showed that in fact the mouth of the cyst was at the level of the pons on the left side (Fig. 4).

\section{CASE 2}

A 7 month old baby was referred in 1967 with history of rapid enlargement of the head, lethargy and lack of interest in her surroundings. No con:

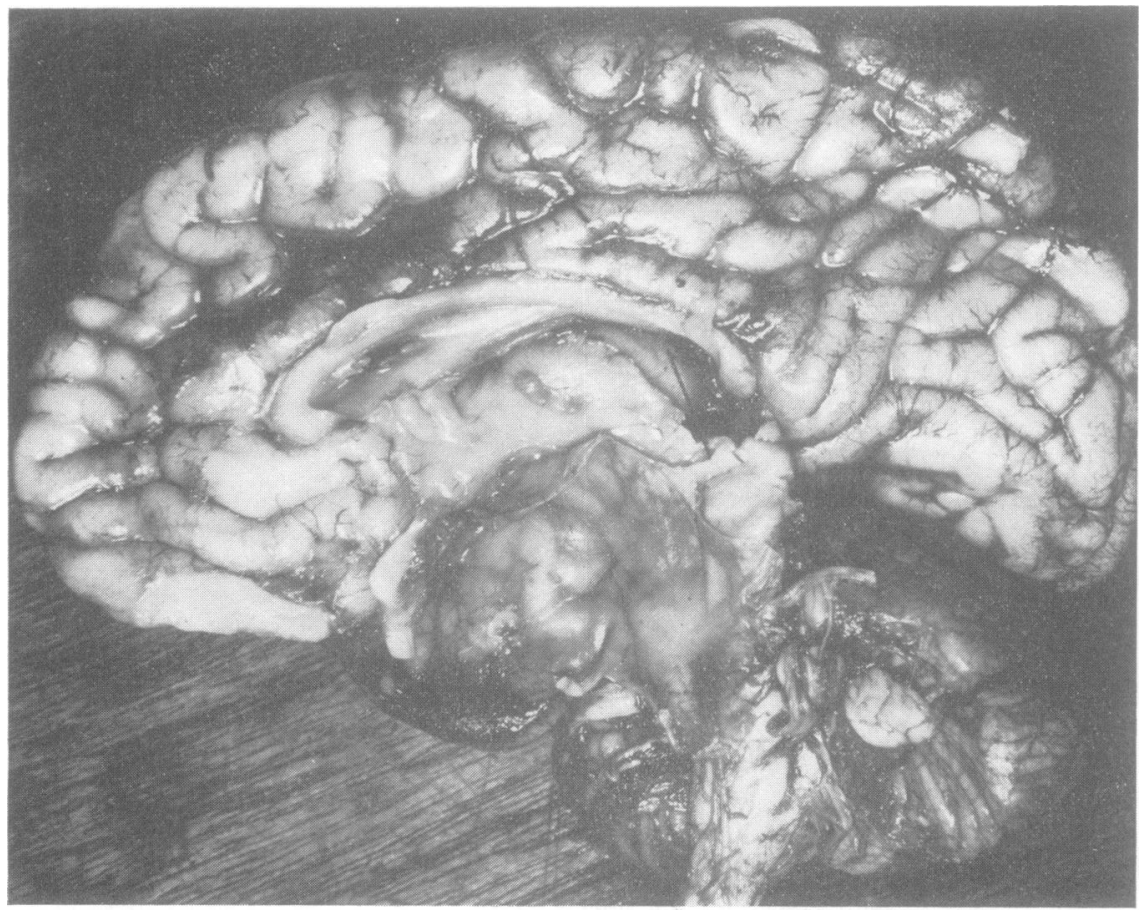

FIG. 4. Case 1. The medial surface of the right cerebral hemisphere. A bristle has been placed in the aqueduct. 


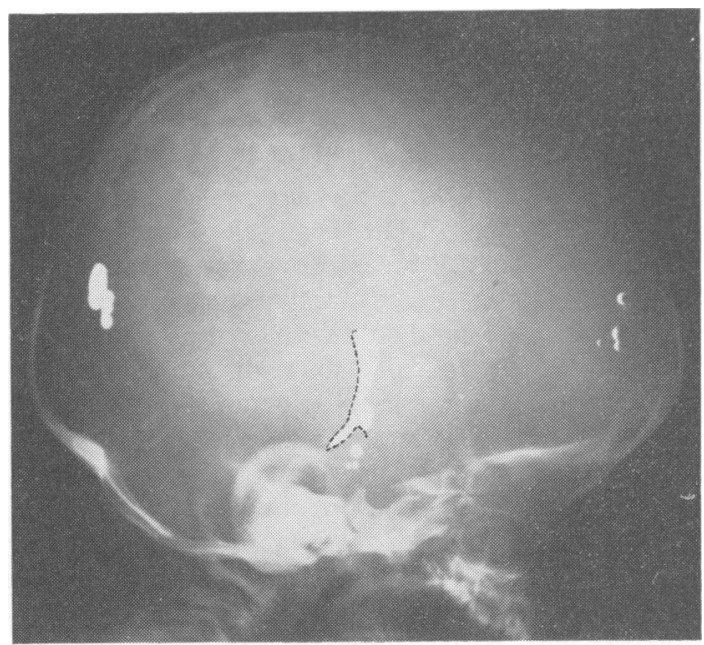

FIG. 5. Case 2. Iophendylate ventriculography showing an enormous hydrocephalus with a convex indentation of the back of the third ventricle and an upward displaced tapered aqueduct.

tributory factors were apparent in the birth and family history.

On examination she weighed $8,500 \mathrm{~g}$; the head circumference was $52.5 \mathrm{~cm}$ with a tense fontanelle, marked sutural separation and 'setting-sun' appearance of the eyes. Subdural taps were negative and the cortical thickness was estimated at $1 \cdot 5 \mathrm{~cm}$. Iophendylate ventriculography showed gross enlargement of the third ventricle with a large suprapineal recess. Only the upper part of the aqueduct was seen and this was tapering in outline and markedly displaced forwards (Fig. 5) but not deviated from the midline. A preoperative diagnosis of possible supracerebellar arachnoid pouch was made and a right occipital craniotomy performed. The tentorium, which was in the normal position, was split, revealing a huge cystic cavity from which escaped clear colourless CSF, below which lay the cerebellum. It was evident that this cavity was in communication with the ventricular system, for as soon as it was opened the right cerebral hemisphere collapsed and was reinflated only partially and with difficulty, each injection of saline being immediately followed by a further escape of fluid from the cyst.

The baby's recovery from this operation was complicated by the development of a subdural effusion which required aspiration on four occasions over 10 days. Thereafter there was no further evidence of increased intracranial pressure and two months after operation the head circumference was $51 \mathrm{~cm}$. At the age of 2 years 8 months it was reported that she was able to stand only with support and to be very ataxic, though able to feed herself and play with toys. The fundi were normal and there was no squint. She was able to say a few words but her mental age as estimated on the Cattell Scale was 12 months and her social age 17 months.

Since then she has remained in good health. At the most recent examination (May 1973) she was attending a school for mentally and physically handicapped children, her social age as measured on the Vineland Scale being 4 years, with a similar mental age. She was still ataxic but able to use scissors and to complete simple jigsaw puzzles.

\section{CASE 3}

This girl was born in May 1958 by normal delivery, weighing $3 \cdot 200 \mathrm{~g}$. She learned to walk at 8 months and said a few words at 11 months. A squint developed at the age of 2 years and was surgically corrected. Her breasts became prominent at the age of 7 years. She presented aged 8 years with a history of repeated falling, at which stage her school work was said to be satisfactory but formal testing showed a full-scale IQ of 66. She was slightly incoordinate and had a genu valgum. One year later she began to have obvious difficulties with school work and continued to fall frequently, sustaining two separate arm fractures. Menstruation began at the age of 10 years.

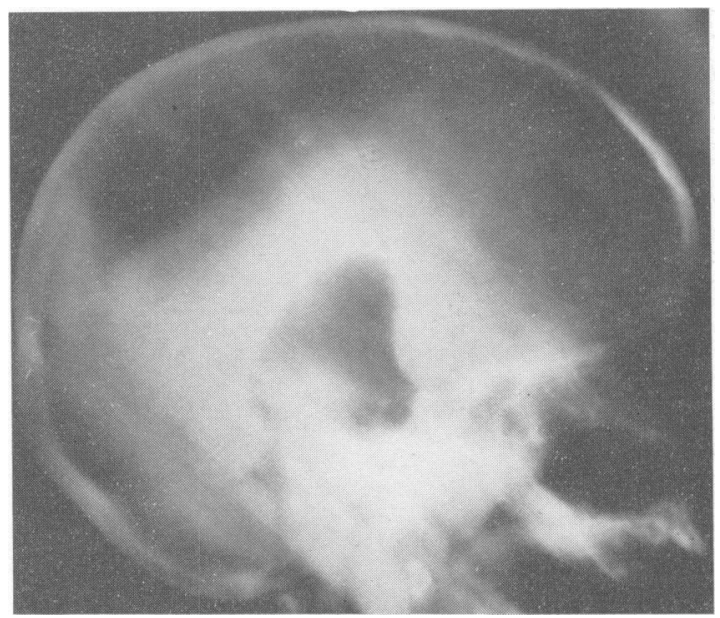

FIG. 6. Case 3. Lateral autotomogram during pneumoencephalography. Note the bulge of the lamina terminalis into the pouch and temporary occlusion of the aqueduct by the bubble which occupies the pouch. 


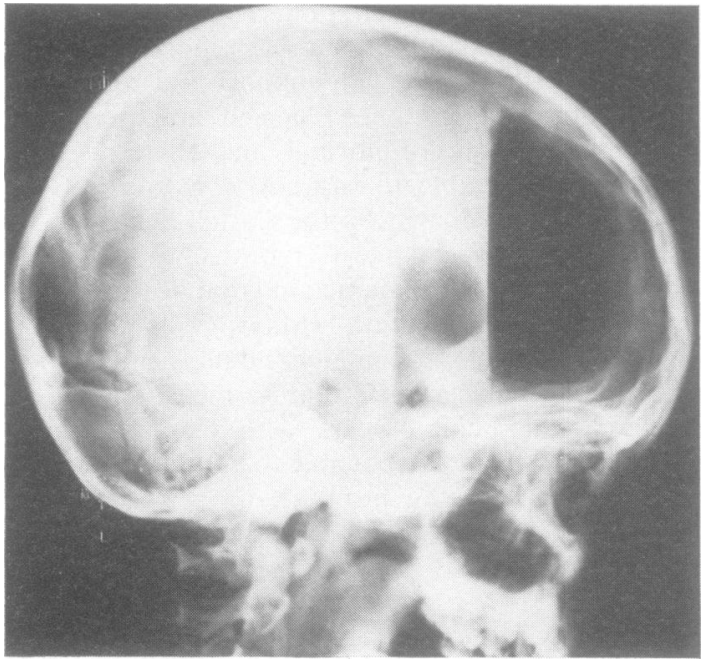

FIG. 7. Case 3. Supine lateral view showing the hydrocephalus and the extent to which the lamina terminalis bulges forward in this position. It confirms that the air within the pouch does not empty forwards.

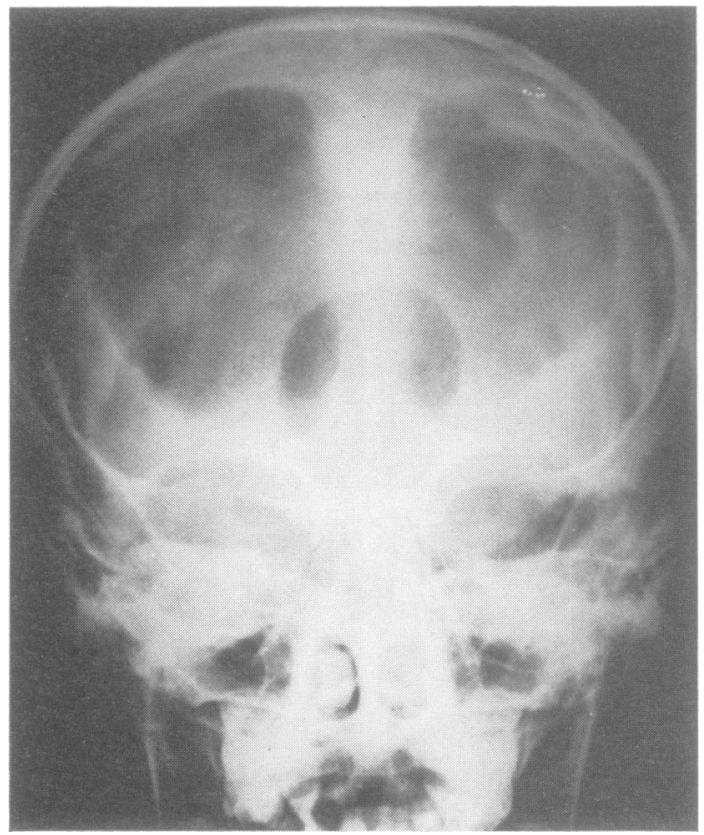

FIG. 8. Case 3. A.P. radiograph of the supine pneumoencephalogram confirming the midline location of the pouch.
In 1970 (aged 12 years) she was an abnormally quiet girl; on formal psychometric testing her IQ o was less than 46 though she had a reading age of $11 \frac{1}{2} \underset{\overline{0}}{ }$ years. Her manual speed was assessed with a peg- $\square$ moving task (mean score 100, SD \pm 15 ): the right hand score was 44 , while no tests could be completed with the left hand. The head circumference was $54 \mathrm{~cm}$. She had full breast development and pubic hair. The cranial nerves and arms were normal. The legs were thin and cold with erythema ab igne of both shins. The left calf was $1 \mathrm{~cm}$ thinner than the right, the left ankle jerk being depressed but the left plantar response extensor. She was unable to cooperate in sensory testing.

An electroencephalogram showed an immature record with a slow wave abnormality associated with $\overrightarrow{0}$ sharp waves in the right frontotemporal region. Radiographs of the skull were suspicious of hydrocephalus with a low torcular: radiographs of the spinal column did not show any abnormality. The bone age at the wrist and elbows corresponded to 14 or 15 years. Pneumoencephalography showed hydrocephalus with early entry of air into the ventricles but air also entered a large cavity lying i $\overline{0}$ the midline between the cerebral peduncles and dis of placing the third ventricle and anterior aqueduct up $\vec{\oplus}$ 을

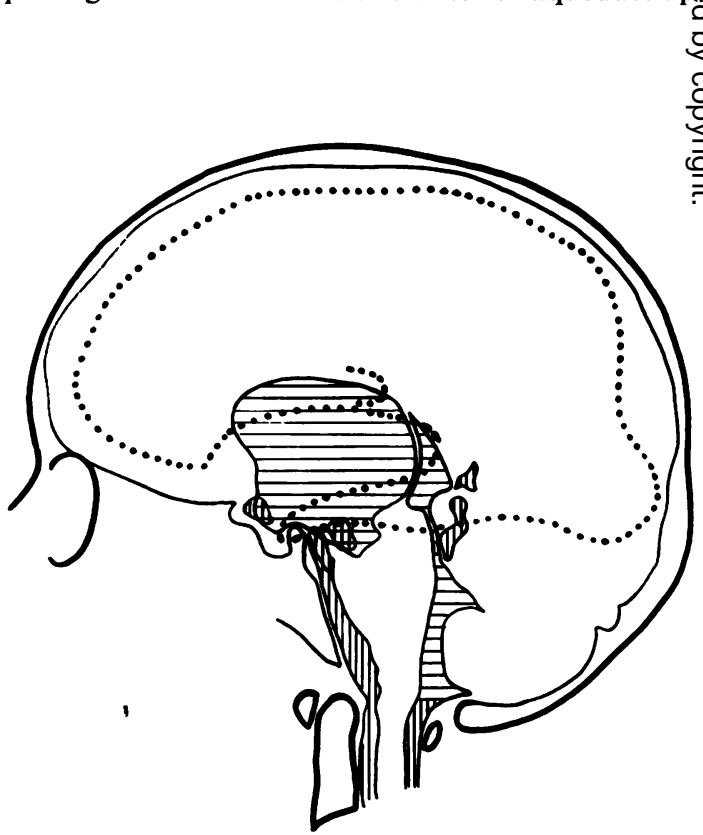

FIG. 9. Case 3. Composite diagram from the pneumoencephalogram and ventriculograms to show the extent of the hydrocephalus, the mean position of the $\mathrm{N}$ pouch and the hold up of air below the incisura. The N air in the pouch and ventricular system is shaded at $\mathrm{N}$ right angles to that in the subarachnoid space. 
wards (Fig. 6). Its front wall changed position by 2.5 $\mathrm{cm}$ with altering positions of the head (Figs 7 and 8). There was communication with the subarachnoid pathways but not apparently with the ventricular system, for a septum could always be seen between the cyst and the third ventricle (Fig. 9).

A ventriculoatrial shunt was performed using a low pressure Holter valve (22 February 1971).

Postoperatively, the girl communicated more freely and was able to resume spontaneous activity such as knitting. When reassessed by psychometry on 8 March she tried to answer more questions and her performance-scale IQ was 55, full-scale 53. She remained well until June 1971 when she had an attack of headache and lethargy accompanied by vomiting during which she held her head bent forward. This persisted for several days. She was admitted to hospital but all her complaints resolved after a few days regular 'pumping' of the valve. When assessed in midsummer 1972 she was attending a special school and still had a tendency to stumble but she no longer complained of headaches, enjoyed doing errands, and was much more talkative and active than previously. She continued to menstruate regularly and her secondary sexual development was unchanged.

\section{DISCUSSION}

Abnormal cystic collections of CSF or CSF-like fluid within the neuraxis may be 'passive' in the sense that they do not compete for space and raise the intracranial pressure; this would seem to be the state of affairs with cysts of the cavum septi pellucidi, an example of which was seen in case 1 as an incidental finding, as well as with those of the cavum vergae and with most porencephalic cysts. Cysts occurring within tumours must clearly be regarded as 'active', but there are also many non-neoplastic collections of intracranial fluid which actively expand, including the ventricular system as a whole in cases of hydrocephalus as well as such localized dilatations as Dandy-Walker cysts and loculations of the temporal horn. In these, the dilating force-following the experimental work of Dandy (1921) - is generally thought to be the secretory pressure of the choroid plexuses, but in cases in which the cyst contains no choroid plexus this explanation is inapplicable. Among these latter, the arachnoid cysts are rare but protean in their manifestations and their sites. They are found in the basal cisterns (Craig, 1932) and particularly in the posterior fossa (Horrax, 1924;
Kaplan, 1948; Gilles and Rocket, 1971). Many cases such as the present case 3 and that of Faris et al. (1971) arise at the point where the CSF pathways pass through the incisura, both anteriorly as here and around the quadrigeminal cistern (Harrison, 1971); some occur along the Sylvian fissures (Dott and Gillingham, 1958; Starkman Brown and Linell, 1958; O'Connell, 1970).

Such cysts have often been classified according to the histology of their walls. Jakubiak et al. (1968) reported two cases of benign solitary supratentorial brain cysts which they believed to have originated from solitary nodules of glial tissue of the type found in the subarachnoid space and described by Cooper and Kernohan (1951) as containing ependyma-lined cavities; they held that it is possible for an 'epitheliumlike lining' to maintain a secretory function, but equally there is no reason why this should not have an absorptive function too. It seems improbable that a completely closed cyst would show a steady expansion unless secretory elements such as choroid plexus or tumour tissue were present in its walls.

Starkman et al. (1958) described a number of cysts which they considered to be formed by splitting or duplication of the arachnoid mater. They postulated a 'focal derangement' of the normal processes of development and stressed that in only one case was there proven sepsis with inflammation of the meninges. Some degree of arachnoiditis is common in association with subarachnoid pouches however, and cases are reported by Horrax (1924) and Craig (1932).

It is unfortunate that, since the operative findings are usually a surprise, many of these casesincluding our own-have not been investigated as fully as one might have wished. Often no cyst-fluid has been obtained for analysis and it is difficult at operation to determine whether or not a small communication exists between the cyst itself and the rest of the subarachnoid space. The cases of Jakubiak et al. (1968) and even the tegmental ependyma-lined cyst described by Hamby and Gardner (1935) might have had tiny communications with the CSF pathways. In the latter case, the cyst fluid was similar to ventricular CSF with a total protein content of less than $10 \mathrm{mg}$ per $100 \mathrm{ml}$ and a negative Pandy reaction.

In our three cases, however, there can be no 


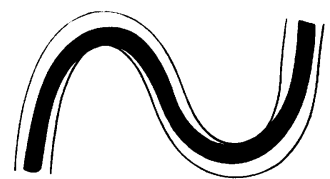

(a) (b)

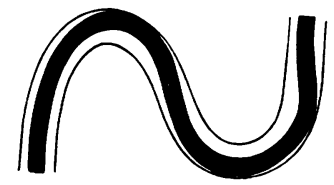

FIG. 10. A diagrammatic representation of an artery within a perivascular sheath to show how change in length of an artery from position (a) to position (b) might conceivably have a pump-like action. Some elongation of arteries may take place during systole but since CSF can flow around the wall of the artery and the artery must fall back to a diastolic position between beats any pumping action must be inefficient.

doubt that the cysts were in direct communication with the subarachnoid space, as demonstrated in two cases by radiological studies and in the other by direct perfusion, and it seems to us that the most likely explanation of why they expanded to the extent of distorting and compressing other intracranial structures is one based upon the effects of pulsation (O'Connell, 1943, 1953, 1970).

Pulsatile energy reaches the neuraxis by two routes, the arterial which conducts cardiac energy and the venous which conducts energy from the abdominothoracic cavity during respiration, coughing, straining, and so on. It has been suggested that arteries lying in the subarachnoid space might act as pumps, especially if closely surrounded by arachnoid adhesions (Dott and Gillingham, 1958), the suggestion being that each systolic pulsation would cause lengthening and therefore undulation of the walls of the artery which would function as a sort of externally directed peristaltic wave. But, since the artery would drop back to its diastolic position between each systole, the driving force would depend upon the difference between the rate of movement of the artery from the diastolic to the systolic position and that at which it returned from the systolic position to the diastolic. That there is such a difference is probable from the shape of the blood-pressure waves, but as a basis for a pump it is very inefficient. The working of a pump based upon the snake-like writhings of arteries is also dependent upon the arteries being closely ensheathed in arachnoid adhesions of such a form as to prevent backward leakage. If the perivascular sheath portrayed in Fig. 10, for example, were circular in crosssection, there would be leakage around the outside of the artery and any pumping action would once again be dependent on a differential in the rate of movement. Considerations such as this make the idea of a pump driven by changes in length of arteries very difficult to substantiate and there is no evidence that such a mechanism is operative. It is true that if, in model hydro dynamic situations, a wave of distension is propagated down an elastic-walled tube lyin 8 within a rigid one, energy may be transmitted $t \&$ the fluid which intervenes between them (Fig. 11) But du Boulay (1966) has shown, and our operas tive observations confirm, that intracrania arterial diameters show very little increas. during systole.

On the other hand, the contours of the subarachnoid space are very responsive to changes in venous pressure, since the membranes by which it is separated from the intracranial and intraspinal veins are pliant (Bedford, 1935). Du Boulay et al. (1973) have shown that, while there is a movement of CSF along the aqueduct of the order of only $0.1 \mathrm{ml}$ per cardiac pulsation, during coughing and straining between 2 and $9 \mathrm{ml}$ of CSF are displaced through the upper cervical spinal canal, the initial movement being always upwards. Venous pulsations of up to $100 \mathrm{mmHg}$ amplitude may be produced during coughing

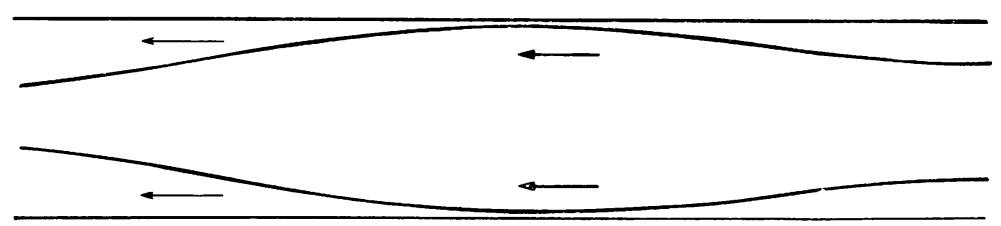

FIG. 11. A wave of distension passing down a tube may impart motion to a fluid lying outside itself within a relatively rigid external tube. Intracranial arterial diameters, however, do not visibly increase with systole. 
(Williams, 1972) and transient pressure gradients of the order of $10-20 \mathrm{mmHg}$ between the two ends of the spinal canal are frequent (unpublished observation). In the cases reported here, and especially in cases 1 and 3, the shape and situation of the pouches was consistent with distension from below.

The relationship between the arachnoid pouch and the hydrocephalus in our three cases is unclear. On the one hand the subarachnoid pouch may have caused hydrocephalus by obstructing the back part of the third ventricle. If the mouth of the cyst is larger than the foramina of Luschka and Magendie, then, during the upward movements of the CSF which occur during coughing, crying, or straining, fluid will be propagated more readily into the cyst than into the ventricular system causing the enlargement of the former, while as the pressure falls again fluid will leave the cyst more rapidly than it leaves the ventricles so that the ventricular system will tend to expand.

Alternatively, one must suppose that the hydrocephalus was primary and the cyst secondary, although even so the cyst might contribute to the progression of the hydrocephalus by occasional compression of the aqueduct. If so, this is one way in which a hydrocephalus leads to its own exacerbation, two others being the flattening of the subarachnoid spaces and the compression of the aqueduct at the incisura due to the pressure of structures competing forspace (Williams, 1973).

We do not believe that in these cases the cysts were previously empty clefts which in cases 2 and 3 became filled with air only during pneumoencephalography. Their size alone makes this unlikely and precocious puberty (as seen in case 3 ) is known to occur in some space-occupying lesions of the posterior end of the third ventricle (Troland and Brown, 1948; Northfield and Russell, 1966) including an arachnoidal cyst (Faris et al., 1971). Hydrocephalus alone is sometimes reported as a cause of precocious puberty (Bourneville and Noir, 1900; Dorff and Shapiro, 1937) but this is uncommon.

The treatment selected for such cases depends upon the surgeon's concept of the original lesion. Subarachnoid pouches along the Sylvian fissure do well when widely opened on to the convexity of the hemisphere or into the basal cisterns. This procedure was adopted with success in case 2 as also by Faris et al. (1971), but in case 1 there was haemorrhage into the cyst cavity with a fatal issue.

In case 3 it was thought that the principal cause of the child's dementia was the hydrocephalus. A ventriculoatrial shunt was safely inserted as a primary procedure, rather than after craniotomy and opening the cyst as recommended by Harrison (1971), whereafter the child's performance in psychometric testing improved as much as could be expected considering her gross cortical atrophy. Possibly the presence of a shunt altered the state of filling of the spinal veins and thus diminished the upthrust on coughing and straining. When the intracranial pressure is low these veins tend to remain full so that the displaceable volume of CSF is, as it were, preempted and the volume displacements are less. Such effects may be seen in a demonstration analogue for ventricular and intraspinal dynamics (Williams, 1974) and may be responsible for the improvement which has been reported in some cases of syringomyelia after insertion of a lowpressure CSF drainage system (Krayenbühl and Benini, 1971). Until more is known of the nature of pulsation within the neuraxis, the best classification and optimum methods of treatment of lesions of this sort will remain obscure.

\section{REFERENCES}

Bedford, T. H. B. (1935). The effect of increased intracranial venous pressure on the pressure of the cerebrospinal fluid. Brain, 58, 427-447.

du Boulay, G. H. (1966). Pulsatile movements in the CSF pathways. British Journal of Radiology, 39, 255-262.

du Boulay, G. H., O'Connell, J. E. A., Currie, J., Bostick, T., and Verity, P. (1972). Further investigations on pulsatile movements in the cerebrospinal fluid pathways. Acta Radiologica, 13, 496-523.

Bourneville, D. M., and Noir, J. (1900). Hydrocéphalie. Progrès Médical (Paris), 12, 17-23.

Cooper, I. S., and Kernohan, J. W. (1951). Heterotopic glial nests in the subarachnoid space: histopathologic characteristics, mode of origin and relation to meningeal gliomas. Journal of Neuropathology and Experimental Neurology, 10, 16-29.

Craig, W. McK. (1932). Chronic cystic arachnoiditis American Journal of Surgery, 17, 384-388.

Dandy, W. E. (1921). The cause of so-called idiopathic hydrocephalus. Johns Hopkins Hospital Bulletin, 32, 67-75.

Dorff, G. B., and Shapiro, L. M. (1937). A clinicopathologic study of sexual precocity with hydrocephalus. American Journal of Diseases of Children, 53, 481-499.

Dott, N. M., and Gillingham, F. J. (1958). Mechanical aspects of the cerebrospinal fluid circulation-physiological, pathological, surgical. In The Cerebrospinal Fluid, Ciba 
Foundation Symposium, pp. 246-264. Edited by G. E. W. Wolstenholme and C. M. O'Connor. Churchill: London.

Faris, A. A., Bale, G. F., and Cannon, B. (1971). Arachnoidal cyst of the third ventricle with precocious puberty. Southern Medical Journal, 64, 1139-1142.

Gilles, F. H., and Rockett, F. X. (1971). Infantile hydrocephalus: retrocerebellar 'arachnoidal' cyst. Journal of Pediatrics, 79, 436-443.

Hamby, W. B., and Gardner, W. J. (1935). An ependymal cyst in the quadrigeminal region. Archives of Neurology (Chic.), 33, 391-398.

Harrison, M. J. G. (1971). Cerebral arachnoid cysts in children. Journal of Neurology, Neurosurgery, and Psychiatry, 34, 316-323.

Horrax, G. (1924). Generalized cisternal arachnoiditis simulating cerebellar tumor: its surgical treatment and endresults. Archives of Surgery, 9, 95-112.

Jakubiak, P., Dunsmore, R. M., and Beckett, R. S. (1968). Supratentorial brain cysts. Journal of Neurosurgery, 28, 129-136.

Kaplan, A. (1948). Pia-arachnoidal cysts of the posterior fossa. American Journal of Surgery, 76, 102-106.

Krayenbühl, H., and Benini, A. (1971). A new surgical approach in the treatment of hydromyelia and syringomyelia. Journal of the Royal College of Surgeons of Edinburgh, 16, 147-161.
Northfield, D. W. C., and Russell, D. S. (1967). Pubertas praecox due to hypothalamic hamartoma. Journal of Neurology, Neurosurgery, and Psychiatry, 30, 166-173.

O'Connell, J. E. A. (1943). The vascular factor in intracrania pressure and the maintenance of the cerebrospinal fluid $T$ circulation. Brain, 66, 204-228.

O'Connell, J. E. A. (1953). The cerebrospinal fluid pressure $\frac{\widehat{\Upsilon}}{\supset}$ as an aetiological factor in the development of lesions affecting the central nervous system. Brain, 76, 279-298.

O'Connell, J. E. A. (1970). Cerebrospinal fluid mechanics. Proceedings of the Royal Society of Medicine, 63, 507-518.

Starkman, S. P., Brown, T. C., and Linell, E. A. (1958). Cerebral arachnoid cysts. Journal of Neuropathology and Experimental Neurology, 17, 484-500.

Troland, C. E., and Brown, C. A. (1948). Precocious puberty of intracranial origin. Journal of Neurosurgery, 5, 541-555.

Williams, B. (1972). Combined cisternal and lumbar pressure recordings in the sitting position using differential mano- of metry. Journal of Neurology, Neurosurgery, and Psychiatry, $\overrightarrow{0}$ 35, 142-143.

Williams, B. (1973). Is aqueduct stenosis a result of hydrocephalus? Brain, 96, 399-412.

Williams, B. (1974). D.A.V.I.D. A demonstration analogue for ventricular and intraspinal dynamics. Journal of Neurological Sciences. (In press.) 